\title{
Neurocriminologia, neurociência e o comportamento criminoso
}

\author{
Neurocriminologia, neurociência e o comportamento criminoso
}

\author{
Joyce da Silva Pereira Marino ${ }^{1}$, Tamires Jordão Laport ${ }^{2}$ \\ Como citar esse artigo. MARINO, J. S.

\section{Resumo}

P; LAPORT, T. J. Neurocriminologia, neurociência e o comportamento criminoso. Mosaico - Revista Multidisciplinar de Humanidades, Vassouras, v. 12, n. 3, p. 41-49, set./ dez. 2021.

Nota da Editora. Os artigos publicados na Revista Mosaico são de responsabilidade de seus autores. As informações neles contidas, bem como as opiniões emitidas, não representam pontos de vista da Universidade de Vassouras ou de suas Revistas.

O presente estudo assumiu como objetivo o papel de propor uma discussão teórica e atual sobre a transformação do paradigma no interior da Criminologia, superando uma perspectiva apenas sociológica, para englobar os aspectos biológicos e físicoquímicos na análise de impulsos e da personalidade de criminosos e suas repercussões práticas. Desse modo, são trazidas para o debate a Neurociência e a Neurocriminologia, campos que vêm ocupando posições de destaques não só nos meios acadêmicos vinculados à Criminologia e à Psicologia, mas que também vêm conquistando importante espaço no cotidiano como prática nos departamentos e por profissionais da Criminologia. Para tanto, a partir de uma Revisão de Literatura, percorre-se o histórico de evolução e o processo conceitual que esteve no centro das teorias realizadas sobre Criminologia desde o que se discute a dicotomia entre impulso inato X condicionamento social. Portanto, trata-se de um debate que se inscreve na esteira das transformações do campo criminológico, com especial enfoque no efeito gerado a partir do advento de equipamentos e recursos tecnológicos, potencializados pelas neurociências, como a neuroimagem.

Palavras-chave: Neurocriminologia; Criminologia; Neurociência.

\begin{abstract}
The present study assumed the role of proportion in a theoretical and current discussion about the transformation of the paradigm within Criminology, surpassing a purely sociological perspective, to encompass the biological and physical-chemical aspects in the analysis of impulses and the personality of criminals and its practical repercussions. In this way, Neuroscience and Neurocriminology are brought to the debate, fields that occupy prominent positions not only in academic circles linked to Criminology and Psychology, but which also demanded the important space in daily life as a practice in departments and by Criminology professionals . Therefore, from a Literature Review, go through the history of evolution and the conceptual process that was at the center of the theories carried out on Criminology since it discusses a dichotomy between initial impulse vs. social conditioning. Therefore, it is a debate that is part of the transformations of the criminological field, with a special focus on no effect generated from the advent of equipment and technological resources, enhanced by neurosciences, such as neuroimaging.
\end{abstract}

Keywords: Neurocriminology; Criminology; Neuroscience.

\section{Introdução}

A neurocriminologia pode ser compreendida como uma subdivisão das ciências criminológicas e da neurociência. Um estudo que faz análise da psicopatia e das atividades criminosas, abordando conceitos referentes à Psicologia Forense e sua aplicabilidade.

Pesquisas neurocientíficas recentes apontam que a influência dos fatores biológicos nas ações cerebrais pode ser determinante para a descoberta dos indícios de um indivíduo possuir ou não predisposição ao comportamento delinquente (AUGUSTO, 2010), colocando em pauta uma nova representação através da qual se pode ver o crime ou a pretensão do indivíduo em cometê-lo.

Dessa forma este trabalho tem o objetivo de dissertar sobre essa ramificação da criminologia aliada à neurociência, o seu impacto na noção que se tem do crime e uma melhor compreensão dos atos violentos e cruéis, ressaltando que a Neurocriminologia como ciência, pode não apenas explicar comportamentos criminosos, mas devido a ela estar aliada a outras ciências como a Sociologia, Psicologia e Biologia, na busca por técnicas que possam auxiliar na investigação de crimes.

A metodologia utilizada trata-se de uma revisão de literatura com consulta a autores especialistas no tema, que será realizada na forma de uma revisão 
narrativa, com a pretensão de explanar os reflexos das descobertas recentes da neurociência relacionadas ao comportamento humano, mais especificamente às suas associações com a violência.

\section{Aspectos Históricos do Estudo da Violência}

Redundante seria argumentar a importância atual de formulações mais aprofundadas sobre a origem do comportamento violento, haja vista a penetração dessa temática nos grandes aparelhos midiáticos, nas redes sociais, nos debates públicos cotidianos. Contudo, a despeito do interesse que o tema notoriamente desperta, nota-se no senso comum e no chamado mainstream pouca variedade de perspectivas analíticas. Daí a relevância de aprofundar esse debate, começando por um balanço histórico sobre as condutas violentas.

Como destacam Santos et al. (2019), essencial para esse ramo da historiografia é a tradição iniciada pelo italiano Cesare Lombroso, a partir da primeira metade do século XIX. Lombroso tornou-se referência, sobretudo, a partir de seu livro "L'Uomo Delincuente", que inaugura uma teoria original no campo da Criminologia: analisando características físicas e mentais de criminosos, o italiano percebe particularidades no crânio dos transgressores (cerebelo menor), levando-o a indagar se "havia no cérebro uma base anatômica para o crime e os criminosos seriam um retrocesso evolutivo das espécies humanas primitivas" (SANTOS et al., 2019, p. 3).

Essa perspectiva determinista e biológica de Lombroso se tornou o aspecto mais conhecido de seu trabalho, mas seu valor para a história da violência vai muito além dessa contribuição. O teórico italiano também foi profícuo na análise dos fatores externos (clima, contexto, costumes), inclusive identificando marcas específicas da civilização moderna como a origem de certos comportamentos criminosos, pois seria uma era cujas exigências de evolução induziriam à "astúcia e fraude" (LOMBROSO, 1899, p. 34).

Desse modo, a importância de Lombroso para a história da violência se justifica pela amplitude de sua teoria, abarcando os dois elementos centrais desse debate: os determinantes biológicos e o condicionamento sociocultural e civilizatório. O antropólogo demonstrou, a partir dessa abordagem transversal, que há aspectos biológicos que remontam as condutas violentas praticadas em todos os períodos da civilização humana (SANTOS, 2008).

E após suas pesquisas científicas passou a defender a teoria de que existe uma conformidade anatômica no cérebro que justifica a conduta violenta e os criminosos seriam um retrocesso evolutivo das espécies humanas primitivas, sendo transmissíveis hereditariamente aos seus descendentes, entendendo o criminoso como alguém que já nasce delinquente, permitindo inferir em suas obras que o criminoso nasce criminoso, não havendo como evitar tal fato. Sua teoria deixou de ser aceita pois ele defendia que para o "criminoso nato" não há escolha, e que este deveria ser excluído do convívio social (NOGUEIRA, 2017). Após a Segunda Guerra Mundial sua teoria entrou em desuso e passou a ser vista como preconceituosa e tendenciosa, sendo substituída por uma concepção sociológica do comportamento, ao entender que a propensão ao crime não está apenas nas condições biológicas, mas também nos fatores externos que norteiam o indivíduo.

Diante dessas reflexões, teóricos contemporâneos e posteriores a Lombroso, como Harris (1993) e Foucault (2001), deram prosseguimento aos estudos históricos da violência, seja em coalizão ou choque com os princípios estabelecidos pelo italiano. Depreende-se das análises desses autores uma diferenciação entre os períodos históricos: na violência transgressora presente na conduta humana de civilizações mais primitivas, era predominante a influência de aspectos biológicos (físicos e mentais), fugindo do comportamento natural dos grupos. Aqui não estamos considerando a violência de proteção ou sobrevivência, haja vista que não compreende um ato deliberado, arbitrário. Já em relação ao ideal de progresso, mobilizado principalmente a partir da migração do povo do campo para a cidade e da cristalização da estrutura social burguesa (divisão social em classes), os ímpetos violentos ganham outros contornos, dessa vez muito mais conectados a aspectos externos, ainda que as razões biológicas não tenham desaparecido.

Tal panorama histórico é essencial para a análise do comportamento criminoso, uma vez que pode ser possível, a partir dessa base histórica, traçar relações entre diferentes contextos, simulando os efeitos deles nas ações humanas, porém sem perder de vista uma perspectiva cientificista, voltada à análise do condicionamento natural (traços de personalidade, processos cognitivos, distúrbios, traumas etc.) como fator elementar do comportamento violento.

\section{Criminologia}

A criminologia é um saber empírico que se originou em meados do século XIX, principalmente pelas teorias de Cesare Lombroso; no entanto, atualmente, esta ciência abrange um campo mais vasto para compreender o comportamento criminoso, evidenciando o crime também como um problema da sociedade. Este estudo aponta que um crime não deve ser julgado apenas pelo ato violento, mas também é de extrema importância compreender a razão que motivou o indivíduo a cometer a ação delituosa. (VERAS, 2006). 
Apesar da Sociologia exercer domínio nos estudos de Criminologia, suas bases vêm se tornando cada vez mais interdisciplinares, dado que também psicólogos, neurocientistas e outros profissionais desenvolvem importantes funções na investigação criminal. Criminologistas se apoiam em vários fatores sobre o crime; muitos desses fatores são de ordem biológica, que analisam a herança genética e as lesões cerebrais; e os fatores de natureza psicológica se apoiam na inteligência e nos traços de personalidade. Existem outros fatores importantes na investigação criminal. É o caso da Neuroimagem, que aprofunda o debate sobre as características biológicas ou não biológicas expressas no comportamento humano (VIANA, 2008).

\section{Uso da Neuroimagem no Entendimento do Cérebro e do Comportamento Humano}

Como antecipado na seção anterior, as teorias de Lombroso foram importantes para muitas descobertas criminológicas, porém atualmente entende-se que é irracional rotular um indivíduo de delinquente pela sua morfologia (MATTOS, 2019). Na atualidade, predominam principalmente duas tendências gerais na interpretação de condutas violentas: 1) o meio, o ambiente e o contexto sociocultural realçam determinados traços temperamentais, advindo de tal combinação comportamentos que se utilizam da violência para obtenção de vantagens materiais ou alívio anímico; 2) o praticante da ação violenta carrega consigo certas características biológicas (físicas e mentais) que conduzem a uma inadequação perante o convívio social e/ou familiar, levando-o a expressar-se a partir da violência ou da transgressão (SILVA, 2004).

Como é possível deduzir, a segunda categoria é mais imprevisível do que a primeira. Isso porque, em se tratando de determinações socioculturais, é possível reconhecer as situações mais propícias para que o ato violento ocorra: ambientes caracterizados pela ausência de uma estrutura familiar, social e de apoio, ambientes fortemente marcados pela inoperância de práticas de mediação de conflito, ambientes de vulnerabilidade social etc. (SILVA, 2004).

É nesse sentido que a Neuroimagem pode ser vista como um instrumento metodológico-científico importante, também, para a Criminologia, já que oferece o auxílio em diagnósticos sobre transtornos psiquiátricos.

Inclusive, nos estudos sobre psicopatia, diversas são as pesquisas com o uso da neuroimagem, muitas delas tem buscado encontrar evidências que confirmem a hipótese de que as bases causais da psicopatia residam na Neurobiologia. Contudo, não há uma conclusão definitiva sobre qual a real causa do comportamento psicopático, embora saiba-se que a base neurobiológica desempenhe papel importante (SOUSA; MATTOS, 2019).

Assim, sendo a neuroimagem um instrumento que pode ser usado também para analisar alterações cerebrais, seu uso pode oferecer benesses significativas para que se compreendam as maneiras de manifestação dessas ações violentas, porém ela por si só não determina as alterações no comportamento violento (SANTOS, 2018, p. 64).

Com relação ao proposto, Mattos (2019) aborda que essa evolução científica que usa métodos não invasivos, que possui condições de analisar o cérebro e seu funcionamento, haja vista que este é fator elementar para o comportamento humano, tornou possível verificar que não existe um modelo pronto, pois os fatores genéticos, o histórico de construção do sujeito e as variações cerebrais são determinantes para modelar o comportamento de formas diferentes.

\section{Sobre a Neurocriminologia}

A discussão proposta até aqui demonstra uma forte inclinação pela interdisciplinaridade para a formulação e aplicação de métodos de previsão e prevenção do comportamento criminoso. No caso da análise histórica da violência, destacou-se uma perspectiva que caminhava entre a Antropologia e a Biologia, mas não sem adentrar constantemente as áreas das Ciências Sociais, Estudos Culturais, Psicologia etc. Em seguida, ao apresentar a Neuroimagem, a tônica não foi outra: o que esse instrumento propõe é uma união entre as áreas biológicas e a análise de contexto que caracteriza a Criminologia.

Quando tratamos de Neurocriminologia essa tendência que passa pela interdisciplinaridade se mantém. Como demonstra Adrian Raine, um dos percursores da Neurocriminologia (RIVERO, 2016), esta área do conhecimento também é fruto do fluxo entre diferentes disciplinas, fornecendo à análise um alcance ainda não experimentado. Especificamente no caso da união entre Neurociência e Criminologia, essa interdisciplinaridade teria duas bases essenciais. A primeira delas está vinculada ao desenvolvimento dos métodos de decodificação da genética molecular, o que permitiu demonstrar a conexão entre certas marcas biológicas e comportamentos humanos (RAINE, 2015). Já o segundo elemento basilar trata-se da ampliação do uso de técnicas de Neuroimagem, anteriormente mencionado.

A partir desses movimentos, o campo na Criminologia passou a contar com instrumentos e recursos que antes não estavam disponíveis. O resultado, naturalmente, foi uma ampliação do horizonte teórico, permitindo conciliar de maneira mais metódica e rigorosa a relação aspecto biológico $\mathrm{X}$ aspecto social 
na análise de comportamentos violentos e criminosos. Assim, a Criminologia passou a incrementar o debate teórico com novos ingredientes. Destaca-se, aqui, a importância desse movimento, pois a renovação do campo teórico é indispensável para dar mais fôlego e alcance aos métodos práticos e, nesse sentido, já se flagra importantes expansões no ramo da Criminologia, inclusive na incorporação da Genética Molecular e da Neurociência:

[...] criminologistas de destaque em todo o mundo estão [...] reconhecendo o potencial transdisciplinar de uma abordagem biológica não como um desafio competitivo, mas como um empreendimento em conjunto, que combina perspectivas sociais e biológicas (RAINE, 2015, p. 13).

Com efeito, os avanços produzidos pela união entre tecnologia e desenvolvimento científico vêm gerando mudanças constantes nos paradigmas da Criminologia, abarcando com especial força estudos no campo da neurociência. Decorre disso uma observação mais ampla e flexível dos fenômenos criminológicos e dos comportamentos violentos. É para esse sentido que vão, por exemplo, as reflexões de Raine et al. (1994), ao destacarem a importância da Neurocriminologia como tática de prevenção de crimes e comportamentos violentos. Para esses autores, conhecer melhor os elementos biológicos que determinam condutas que fogem à razoabilidade do convívio social pode ser um passo decisivo para lidar com possíveis transtornos e deformidades, possibilitando, assim, que a própria sociedade e o poder público possam adotar práticas de controle e entendimento dos portadores desses distúrbios. Essa perspectiva teórica, portanto, é bem-marcada pela relação entre Criminologia e Saúde Pública:

Destamaneira,Adrian Raine, ao apontaros possíveiscaminhos que a neurocriminologia pode levar, no que tange à prevenção da violência, vai dizer que um dos seus objetivos é "explorar a violência com uma abordagem de saúde pública", cultivando "uma perspectiva mais compassiva, não apenas para com as vítimas, mas também para com os infratores". Dentro dessa perspectiva, com base em estudos neurocriminológicos, são apresentadas uma série de possibilidades de atuação, por meio de políticas públicas, que visam minimizar e, até mesmo, previnir casos de comportamento agressivo. São medidas como melhores condições de nutrição, maiores cuidados pré e pós-natal e programas de instrução de habilidades parentais, por exemplo, que surgem como potenciais mecanismos de aplicação dos conhecimentos advindos da neurocriminologia. (RIVERO, 2016, p. 103)

Em resumo, a abordagem defendida por Raine (2015) coloca em xeque noções unilaterais, que apontam apenas para questões sociais como elemento central das causas de ações criminosas. Dessa forma, ao aprofundar estudos sobre características biológicas - como o reconhecido estudo acerca de bebês com complicações no parto - o teórico inglês encara frontalmente os elementos físico-químicos contidos na composição do impulso violento ou infrator.

Pode-se verificar que, no percorrer da modulação e consolidação da Neurocriminologia, esta é uma nítida tentativa de fornecer mais solidez à análise criminológica. Isto é, considerando que o contexto social é dinâmico e fragmentado, tomá-lo como única fonte de promoção e estímulo de ações criminosas, além de configurar uma limitação teórica, representa a aceitação da impossibilidade de agir preventivamente: se cada contexto social apresenta particularidades, como criar procedimentos de prevenção mais amplos e globais?

A Neurocriminologia advém dessa demanda técnica, sustentada na noção de que apenas as análises de cunho sociológico não dariam conta de identificar padrões e parâmetros que serviriam de base para prever e prevenir crimes e violências. Era preciso abrir o campo de análise, em vez de limitá-lo, e a Neurocriminologia, na medida em que busca identificar a raiz mais profunda dos comportamentos intempestivos e transgressores as características biológicas contidas nos processos cognitivos de criminosos -, persegue uma perspectiva mais global e integral. (SIQUEIRA, 2004).

\section{Mapeando o Cérebro com as Novas Neurotecnologias}

Assim como, praticamente, em todas as áreas do conhecimento da Era Moderna, a Neurociência sofre impacto decisivo do desenvolvimento das tecnologias e do tecnicismo. Esse movimento opera uma mudança de paradigma importante, adicionando novos elementos na interpretação do comportamento humano (AUGUSTO, 2010).

A partir do período oitocentista, cria-se uma tradição criminológica que vai expandindo os horizontes, inaugurando novas linhagens teóricas com base nas formulações de especialistas como Lombroso, Kurella, Guiteau e Gray, entre outros (AUGUSTO, 2010).

Merece menção, nesse processo, a percepção assumida de que o cérebro possui um contexto interno, biológico, a despeito de um determinismo sociológico. O resultado prático disso é a assimilação dos processos cognitivos como eventos em si, não necessariamente condicionados por influências externas. A título de exemplo: mapeando e caracterizando os movimentos cerebrais, percebe-se que determinados comportamentos foram mobilizados internamente, independentemente do que circundava o indivíduo socialmente constituído. Traumas e distúrbios, dessa forma, são analisados por suas características mais amplas, e menos específicas (SILVA; ORTEGA, 2016). Para tanto, indispensáveis foram as novas tecnologias: 
As descrições de imagens, especialmenteas docérebro, atraem por todo o arco-íris de cores e gradações. Os tomógrafos com tecnologia de ponta, que realizam exames conhecidos como "Positron Emission Tomography" (PET - tomografia de emissão positrônica), "Single Photon Emission Computed Tomography" (SPECT - tomografia computadorizada por emissão de fóton único), "Computerised Tomography" (CT - tomografia computadorizada) e "Functional Magnetic Resonance Imaging" (fMRI - ressonância magnética funcional), promovem uma aura de fetichismo em torno da caixa preta que é o cérebro, estabelecendo a crença na objetividade da imagem desincorporada e descontextualizada. (AUGUSTO, 2010, p. 63)

Com as novas neurotecnologias podem ser reconhecidas as atividades mentais, sejam elas emotivas ou não, que geram certas movimentações físicas e químicas (magnetismo, metabolismo, sinais elétricos etc.). A despeito de rica diversidade nas perspectivas teóricas da Neurociência, habitam nas principais linhas teóricas uma perspectiva básica: quando são expressas condutas humanas (éticas, morais, políticas, ideológicas), estão em atuação "sistemas neuronais" que constituem a composição fisiológica do cérebro (AUGUSTO, 2010). Portanto, quando é realizada determinada ação, é possível observar, a partir da análise dos processos cerebrais, quais são as características que integram especificamente aquele comportamento.

Augusto (2010) vai chamar esses novos instrumentos e procedimentos, proporcionados pela tecnologia a partir do período oitocentista, de "novas ciências do cérebro", abarcando as experiências teóricas criadas para entender a fisiologia e a biologia do cérebro. Para o autor, à luz das hipóteses de Eastman, Campbell, Morse e Raine, as novas possibilidades proporcionadas pela tecnologia devem se integrar com a área do Direito, considerando os mais diversos aspectos contidos na formação de uma personalidade criminosa. Com isso, toda a lógica de prevenção e condenação de crimes deve ser revisitada e discutida em face desses novos instrumentos; eles influem, inclusive, na maneira de combater os comportamentos criminosos e reconhecêlos.

Pode-se concluir que, por meio da tecnologia, foi alcançada uma apuração científica sobre uma suposição presente na Antiguidade e na Idade Média: a de que criminosos e infratores podem carregar aspectos biológicos que os diferenciem das outras pessoas. No entanto, estas técnicas possuem limitações para explicar os comportamentos e prever ações (MATTOS, 2019). A interpretação de suas imagens envolve questões complexas e que necessitam ser bem analisadas antes de serem usadas como evidência:

Haja vista, estes exames funcionais, com a tecnologia atualmente disponível, podem no máximo servir como ferramenta auxiliar no estudo da criminalidade e não como evidência para justificar, ou até predizer, o comportamento humano. (MATTOS, 2019, p. 13).
É evidente que as neuroimagens se tornaram instrumentos extremamente uteis no diagnóstico de doenças e traumas do cérebro, também no planejamento de tratamento e prognóstico. Todavia, ainda são inconclusivas para provar o comportamento humano, pois cada indivíduo é moldado de acordo com sua vivências aos fatores intrínsecos e extrínsecos (MATTOS, 2019)

\section{A Evolução na Análise do Comportamento Humano}

Impossível é tratar do avanço proporcionado pela Neuroimagem e pela Neurocriminologia sem, antes, dissecar o processo histórico que impulsou a abordagem dessas áreas modernas do conhecimento. Rivero (2016) remonta a importância de Darwin, passando também por Dawkins, para consolidar a perspectiva biológica na definição de um comportamento especificamente humano. Decorre dessa concepção a "psicologia evolucionista", que, incorporando o conceito do evolucionismo darwinista, aprofunda-se na hipótese de que o comportamento humano decorreria do processo de evolução pelo qual passa nossa composição biológica.

Em seguida, (Martin 2015 apud RIVERO, 2016) destaca o impacto produzido pela civilização que conquista um maior controle sobre a natureza. Dotado dos "recursos mais básicos de sobrevivência" (RIVERO, 2016, p. 60), o comportamento humano deve ser analisado sob outro prisma, permitindo uma separação entre conduta primitiva e cultura. Reconhecendo essa nova figura humana como objeto de estudo, exige-se que a análise psicológica e neurológica do indivíduo se expanda, diferenciando o comportamento singular de convenções coletivas, comportamento intuitivo de comportamento condicionado, comportamento ímpar de comportamento padronizado. Tais diferenciações ganham limites mais imponentes entre si conforme se escancara o conflito civilizatório entre universal $\mathrm{X}$ particular ou global $\mathrm{X}$ singular. Uma vez que a singularidade e a particularidade passam a representar valores importantes para as sociedades, as análises sobre a realidade e sobre a natureza sofrem um revés, tendendo para a especificidade e para a tecnicidade.

Deve-se, nesse sentido, retomar a ruptura histórico-civilizatória operada a partir do século XVIII, derrocando no Iluminismo e na Revolução Industrial. Esses eventos buscaram superar o misticismo e teocentrismo que imperavam na Era Medieval, substituindo-os por uma sociedade mais científica e tecnicista, voltada mais ao progresso do que à manutenção dos dogmas. (HOBSBAWM, 2010)

Advém daí o desenvolvimento de diversas áreas específicas do conhecimento, o que foi o pilar da criação das grandes tecnologias que marcam a 
vida moderna. Na consolidação dos campos teóricos, ganha força, no contexto da análise do comportamento humano, a Psicologia, que consegue orientar as investigações pela observação do comportamento de criminosos. A Psicologia aplicada ao âmbito criminal vai se comprometer para que o indivíduo delinquente, seja compreendido como indivíduo e não como o crime cometido, para que o sujeito seja julgado também pelo motivo que o levou a cometer tal delito e não somente pelo ato criminoso (BERTOLDO, 2019).

Estrutura-se, a partir desse contexto histórico, uma produção científica e teórica que trabalhava com a hipótese da natureza do comportamento humano, colocando no centro das análises as diferenças biológicas existentes entre os indivíduos. Em outros termos, começa a ganhar corpo, na interpretação do comportamento humano, a ideia de que existem certas tendências comportamentais determinadas pela composição biológica e fisiológica dos indivíduos (CLARKE; JACYNA, 1987).

Naturalmente, o tema não está liquidado, mas as atuais conquistas, contando com equipamentos e instrumentos muito avançados em relação aos que estavam disponíveis em outros períodos históricos, inclinam cada vez mais as análises do comportamento humano para uma perspectiva neurocientífica, capaz de averiguar tecnicamente os condicionantes internos das condutas humanas.

\section{Considerações Finais}

Pelo que aqui foi exposto, é indispensável reconhecer o valor das novas tecnologias, a Neurocriminologia, fazendo uso de recursos como o da Neuroimagem, passou a contar com uma averiguação científica acerca de impressões esparsas e formulações filosóficas que já se expressavam. Isto é, com a conexão entre Criminologia, tecnologia e Neurociência, foi possível demonstrar cientificamente que pode haver, sim, uma inclinação para ações criminosas, ainda que as condições psicológicas e biológicas não devam ser tratadas como causas únicas. Não se pode negar que a Neuroimagem é um instrumento que revolucionou o diagnóstico e traumas cerebrais, bem como na elaboração de tratamentos. No entanto, ainda é equivocado usá-la para justificar o comportamento humano, sabendo que seria necessário que o indivíduo, submetido ao exame, estivesse sentindo as mesmas emoções de quando praticou o ato criminoso.

Sabe-se que as neurotecnologias são ferramentas com restrições para explicar as ações humanas, pois somente a interpretação de imagens cerebrais não prova as condutas transgressoras, por fazer-se necessário uma análise da subjetividade e construção emocional de cada indivíduo.

Destaca-se, ainda, que a contribuição da Neurocriminologia, enquanto instrumento para investigar crimes, não exclui a importância da análise psicológica, sociológica e sociocultural, mas cede a essas perspectivas novos elementos, enriquecendo e diversificando a análise criminológica.

\section{Referências}

AUGUSTO, C. B. Neurocriminologia: Novas ideias, antigos ideais. Revista Jurídica da Presidência, Brasília, v. 12, n. 96, p. 44-72, fev./maio 2010. Disponível em: https://revistajuridica.presidencia.gov.br/index.php/saj/ article/view/231. Acesso em: 18 fev. 2021.

BERTOLDO, J. M. Psicologia criminal: perfil psicológico para auxiliar investigações criminais. 2019. Monografia (graduação). Univ. Caxias do Sul, Caxias do Sul, 2019. p 46 Disponível em: https://repositorio.ucs.br/ xmlui/bitstream/handle/11338/5025/TCC\%20Juliana\%20Marcela\%20 Bertoldo.pdf?sequence=1\&isAllowed=y. Acesso em: 02 mar. 2021.

CLARKE, E.; JACYNA, L. S. Origens dos conceitos neurocientíficos do século XIX. Berkeley: University of California Press, 1987.

FOUCAULT, M. Microfísica do Poder. Rio de Janeiro: Graal, 2001.

HARRIS, R. Assassinato e Loucura: medicina, leis e sociedade no final do siècle. Rio de Janeiro: Rocco, 1993.

HOBSBAWM, E. J. A era das revoluções: 1789-1848. São Paulo: Ed. Paz e Terra, 2010.

LOMBroso, C. Le Crime, Causes et Remèdes. Paris: Librairie C. Reinwald, Schleicher Frères, 1899.

MATTOS, M. S. S. K. Fundamentos teóricos dos estudos de neuroimageamento associados ao comportamento violento e suas repercussões práticas. 2019. Dissertação. Programa de Pós-Graduação em Cognição e Linguagem (mestrado em Cognição e Linguagem). UENF, Campos dos Goytacazes, RJ. 2019. P 1-91. Disponível em: http://uenf.jvlabs. com.br/arquivos/dissertacaoversaofinal_020920191453.pdf. Acesso em: 17 mar.2021.

NOGUEIRA, M. A. Lineamento histórico da criminologia crítica a partir de algumas escolas de pensamento. 2017. Monografia (graduação). Faculdade de Ciências Jurídicas e Sociais, Centro Universitário de Brasília, Brasília, 2017. p 1-78. Disponível em: https://repositorio.uniceub.br/jspui/ bitstream/235/11641/1/21257995.pdf. Acesso em: 20 mar. 2021.

RAINE, A.; BRENNAN, P.; MEDNICK, S. A. Birth complications combined with early maternal rejection at age 1 year predispose to violent crime at age 18 years. Archives of General Psychiatry, v. 12, n. 51, p. 984-88, 1994. Disponível em: https://jamanetwork.com/journals/jamapsychiatry/articleabstract/496876. Acesso em:11 mar. 2021.

RAINE, A. A anatomia da violência: as raízes biológicas da criminalidade. Porto Alegre: Artmed, 2015.

RIVERO, S. M. Neurocriminologia: (re)pensando a criminologia a partir de diferentes ângulos e abordagens. 2016. Dissertação (mestrado em Ciências Criminais). PUC-RGS, Porto Alegre, 2016. p 11-127 Disponível em: https://repositorio.pucrs.br/dspace/bitstream/10923/10714/1/00048584 1-Texto\%2bCompleto-0.pdf. Acesso em: 28 mar. 2021.

SANTOS, E. M. G. A Face Criminosa. 2008. Dissertação (mestrado em História) UFPE, Recife, 2008. p 10-135 Disponível em: https://repositorio. ufpe.br/bitstream/123456789/7278/1/arquivo3320 1.pdf. Acesso em: 02 abr. 2021.

SANTOS, H. L.etal. Neurociência e o comportamento criminoso: implicações para o direito penal. RCI, v. 4, n. 2, p. 1-17, 2019. Disponível em: https:// unaerp.br/revista-cientifica-integrada/edicoes-anteriores/volume-4-edicao2/3396-rci-neurociencia-e-o-comportamento-criminoso-implicacoes-parao-direito-penal-06-2019/file. Acesso em: 08 abr. 2021.

SANTOS, H. L. Neurociência e o comportamento criminoso: Implicações 
para o Direito Penal. FABE em Revista, Bertioga, v. 8, p. 59-66, 2018. Disponível em: http://fabeemrevista.com.br/material/vol8/05.pdf. Acesso em: 29 mar. 2021.

SILVA, L. A. M. Sociabilidade violenta: por uma interpretação da criminalidade contemporânea no Brasil urbano. Revista Sociedade e Estado, Brasília, v. 19, n. 1, p. 53-84, jan./jun. 2004. Disponível em: $\quad$ http://www.scielo.br/scielo.php?script=sci arttext\&pid=S010269922004000100004\&lng=en\&nrm=iso. Acesso em: 10 fev. 2021

SILVA, L. R. F. ORTEGA, F. A determinação biológica dos transtornos mentais: uma discussão a partir de teses neurocientíficas recentes. Cad. Saúde Pública, Rio de Janeiro, v. 32, n. 8, p. 1-11, 2016. Disponível em: https://www.scielosp.org/article/csp/2016.v32n8/e00168115/. Acesso em: 08 mar. 2021

SIQUEIRA, L. O Renascer da Neurocriminologia. Revista da EMERJ, v. 7, n. 25, p. 96-99, 2004. Disponível em: https://core.ac.uk/download/ pdf/18337062.pdf. Acesso em: 24 mar.2021.

SOUSA, C. E. B.; MATTOS, M. S. S. K. Neuroimagem e Psicopatia: Avanços e Críticas. Ciências \& Cognição, v. 24, n. 2, p. 214-226, 2019. Disponível em: https://www.academia.edu/42216261/Neuroimagem_e_Psicopatia_ Avan $\%$ C3\%A7os_e_Cr\%C3\%ADticas. Acesso em: 05 abr.2021.

VERAS, R. P. Os crimes do colarinho branco na perspectiva da sociologia criminal. 2006. Dissertação (mestrado em Direito Penal). PUC-SP. São Paulo. 2006. p. 1-206. Disponível em: http://dominiopublico.mec.gov.br/ download/teste/arqs/cp012998.pdf. Acesso em: 30 mar.2021.

VIANA, Eduardo. Criminologia. 7. ed. Salvador-BA: Juspodivm 2008, p. 25-34. Disponível em: https://www.editorajuspodivm.com.br/cdn/arquivos/ c1f47536ed2d54224d1240a756968fa6.pdf . Acesso em: 02 mar. 2021.E 


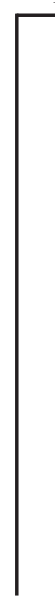




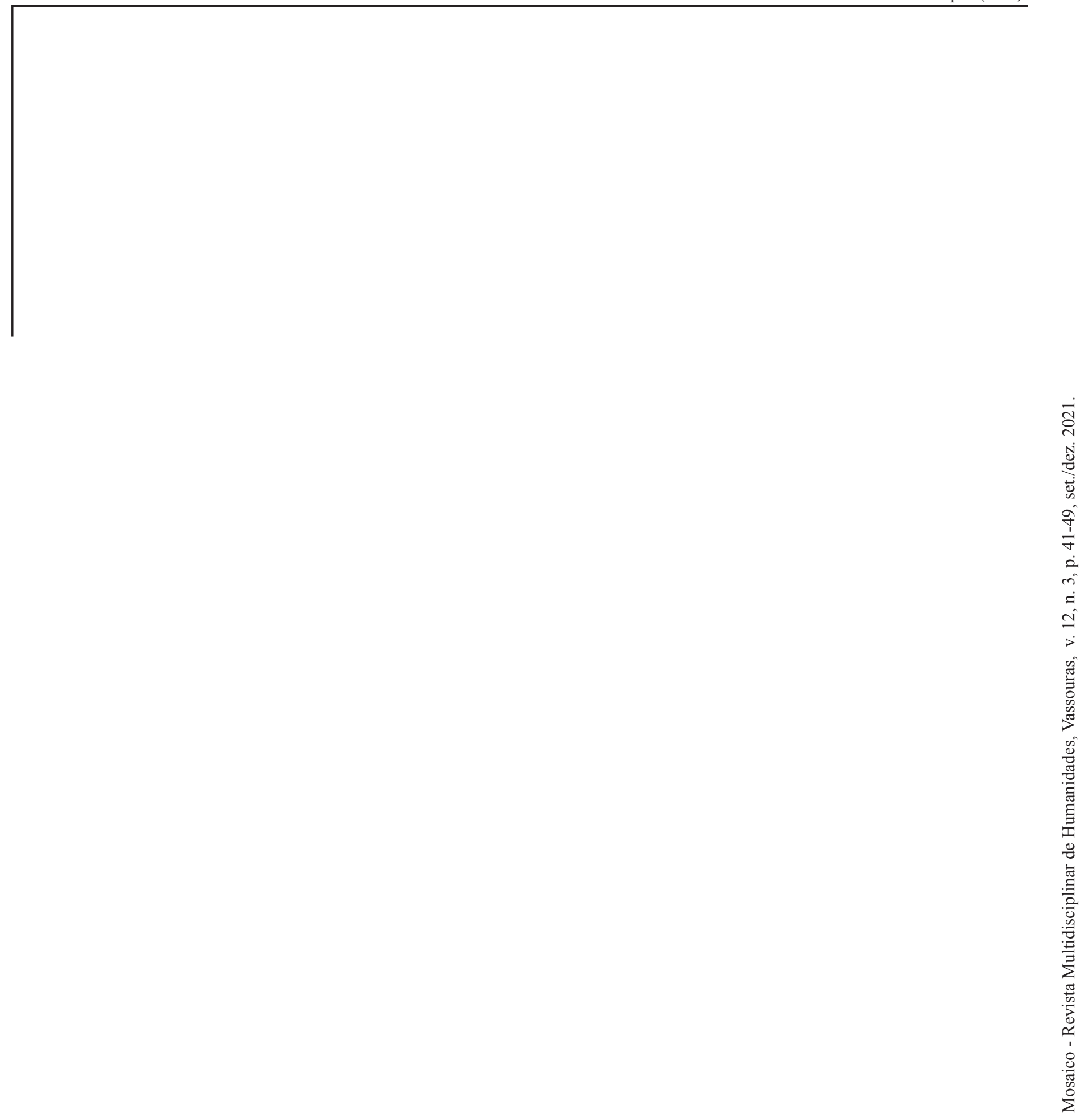

